\title{
An Uncanny Site/Side: On Exposure, Dark Space, and Structures of Fear in the Context of Performance ${ }^{1}$
}

\author{
Maya Nanitchkova Öztürk
}

1. An earlier version of this study was presented at the 2 nd International Conference CTLA, held at the University of Wales, Aberystwyth, 5-7 May 2007, and is included in

Consciousness, Theatre, Literature and the Art. 2007, ed. by Daniel

Meyer-Dinkgrafe (Newcastle:

Cambridge Scholars Publishing, 2007), pp 101-15.

2. Choosing the terms 'site' and/or 'space in the context of performance' was done with the intention of evading established connotations of related terms, such as those of 'theatre space' with regard to 'functions' in the formulation of

\section{Theatre, Fear and Space}

\section{Functions of Space}

This article approaches the site as a corporeal component of theatrical praxis. ${ }^{2}$ It seeks to acknowledge that a subtle dimension of space, the 'bodily' and unmediated, can trigger an experiential mode, infused with feelings, and bearing on the ontological. From this perspective, the site is conceived as an artefact not only because it constructs the presentation of the theatrical work and assists the unfolding of a multi-dimensional performative event, but furthermore, because as space that is formalized, qualified, and effective, it performs as a dynamic constituent of experience. $^{3}$ This article proposes to substantiate such capacities of the site by way of a dramatization of the effects of space, through fear. This offers the opportunity to grasp, within the spatial economy of theatre, certain less-explored operations of space as discrete phenomena that recur and configure a relatively autonomous layer of experience for all participants involved. These phenomena render audiences productive, invigorated through fear, and engaged in the performance.

Comprehensive overviews on theoretical thought from within theatre and/or performance studies point to the particular way in which the role of space is conceptualized - namely, in specific reference to theatrical practices and theatre experience. ${ }^{4}$ As these are rooted in and evolve through the theatrical work and/or event, the major issue is how 'space

\footnotetext{
Maya Nanitchkova Öztürk, Department of Interior Architecture and Environmental Design, Faculty of Art Design and Architecture, Bilkent University, Ankara, Turkey. Email: omaya@bilkent.edu.tr
}

Contemporary Theatre Review ISSN 1048-6801 print/ISSN 1477-2264 online (C) 2010 Taylor \& Francis http://www.informaworld.com DOI: $10.1080 / 10486801.2010 .488840$ 
meaning in theatre, as employed by Gay

McAuley, in Space in

Performance: Making

Meaning in the

Theatre (Ann Arbor:

University of Michigan

Press, 1999), pp. 1-

35. Though coming

close to 'theatre space'

in that it encompasses stage and auditorium,

the 'site' as a principal term allows asserting

reliance on certain

essential charges: it is taken to denote

qualified space which on its own terms

constitutes experience

at various levels and

for all participants

involved. In this sense

it needs to be

distinguished from

'the performance site'

or 'the site', which

would emphasize

space as area of

performance,

presenting a field for

'other' represented

sites, as discussed by

David Wiles, in $A$

Short History of

Western Performance

Space (Cambridge,

New York: Cambridge

University Press,

2003), pp. 1-22

(p. 8).

3. Articulating the potential of space to be suggestive of

experience rather than experientially neutral, this study adopts the notion of the 'performative' with respect to space, denoting its capacity to 'do', distinct from its capacity to 'house' performance practices

This notion is further intimated and explicated in terms of 'experiential consequentiality', centring on circumstances and mechanisms whereby space comes to perform-influence dispositions, propose acts, construct relations-while deterministic underpinnings are, at in performance' supports processes of production and communication of theatrical meaning. ${ }^{5}$ It can be argued that with the re-discovery of the body, the notion of space as a carrier of diverse systems of signs theorized in complex taxonomies of spaces emanating from the stage, is superseded by a paradigm centred on the 'live-ness' of performance-as-event. While this entails constructive involvement of the audience via the principal relations instituted among participants (performer-audience, performerperformer, audience-audience), regarding the experience of the theatrical, the functions of space are still being defined in terms of an array of categories that revolve around the scene as the principal place of performance and are intrinsically entangled with representation. Conceptions of the entire site range from space that 'houses' the experience of the theatrical event in perspectives exploring the various levels of communication involved, ${ }^{6}$ through to space as an 'active agent' 'shaping what goes on within it' in space-centred perspectives. In this, as 'theatre space' comprising stage and auditorium, it presents the physical environment that 'situates' and 'establishes relations' between performers and audience, in the form of an 'apparatus of looks'. As 'theatrical space', it 'emits signals' and provides a 'context of interpretation for performers and spectators alike', where the architectural is but one in the complex interplay of various spaces (such as stage, scenic, dramatic) operating through both physical and fictional elements. ${ }^{7}$ A further shift away from the homogeneity of an 'ocular' space-container which sets the presentation/perception framework is provided by the account of space as an entity that 'enfolds' the event, the performers, and the audience - a tangible presence, tactile and sound reverberating, in which one is immersed. Theatre, thus, is to be 'experienced' in the dialectical relations of diverse architectural environments with various performance practices, where space, analogous to the actors, is made to 'perform' with and in the play-as-event. ${ }^{8}$

In keeping with these priorities, the problem of space in the architectural field takes the form of 'space for performance'. Along with the exterior of the theatre building, architectural attention is given to the formation of stage and auditorium that structures the principal relation relevant to the experience of theatre. This implies that otherwise space would be seen as a relatively neutral background for the constitution of various kinds of performances and diverse theatrical expressions.

\section{Ontological Interruptions}

With such emphasis on the theatrical work/event, the ontological potential of theatre tends to be ascribed to the aesthetic (and represented), thus firmly delineating discussion within these functions of space. Yet it can be argued that theatre, evolving as an amalgam of complex processes, might sustain such constitutive functions at several levels. These become apparent when the ontological is conceived as embedded not precisely in the work of art, but rather in the very interruption brought about by the encounter with it. ${ }^{9}$ Seen as the opening up of linear time, this interruption mobilizes a fundamental mechanism, the potential of which is both aesthetic and ontological. As a 
best, avoided. For further detail on the notion of the performative as 'doing', refer to Nicky Gregson and Gillian Rose, 'Taking Butler Elsewhere: Performativities, Spatialities and Subjectivities', Environment and Planning D: Society and Space, 18 (2000), $433-52$.

4. This brief overview is based on the works of McAuley, Space in Performance, pp. 135, Willmar Sauter, The Theatrical Event: Dynamics of Performance and Perception (Iowa City: University of Iowa Press, 2000), pp. 172 , and Wiles, $A$ Short History, pp. 1-22, 240-66, where each within the specificity of their theoretical perspective discusses diverse frameworks on theatre and space.

5. McAuley, Space in Performance, p. 17.

6. Sauter, The Theatrical Event, pp. 1-113.

7. McAuley, Space in Performance, pp. 25577.

8. Wiles, A Short History, pp. 1-22.

9. Giorgio Agamben, 'The Original Structure of the Work of Art', in The Man Without Content, trans. by Georgia Albert (Stanford, CA: Stanford University Press, 1999), pp. 94103.

10. Ibid., p. 101.

11. Susanne K. Langer, Mind: An Essay on Human Feeling (Baltimore and 'present-ness', when one is arrested 'before' something that is also an 'outside' - 'ek-stasis', it enables a slippage into some more essential dimension of existence. Thus, by attaining one's proper mode of being and reclaiming one's creative capacities, the appropriation of the work becomes also an appropriation of the self.

It is possible to conceive that this mechanism, though perhaps most profound in the compelling presence of an artwork, would be triggered and actualized, analogously, though the disruptive capacities of the event in the contexts of 'ritual and festival'. ${ }^{10}$ In view of these contexts, theatre appears to propose a threefold interruption, where mundane concerns and routines are suspended, to be replaced by the engagement that entails the theatrical work, evolving as a performative event, and firmly set within formalized space. This suggests that in theatre the ontological would involve vital features of the collective event along with its aesthetic qualities. Yet, furthermore, theatre might be construed within a third, corporeal layer, where conditions akin to the 'spatiality' of that fundamental mechanism are reproduced through the body as ambivalent situatedness, as hesitancy over ambiguous impulses borne and/or magnified by space.

\section{Fear - Mediated and Immediate}

The possibility of construing space as the vehicle of the ontological functions of theatre comes forth, when feeling is understood as part of a total phenomenon, and when both the inward emotional life and that which is experienced through the body are acknowledged as a bridge to conscious states. ${ }^{11}$ Yet in discourses on theatre, with artifice and representation considered to be at the core of the theatrical, interpretations of the function of emotions appear in a mediated rather than immediate form. For the audience, these elements tend to be reduced to allusions of fear allotted to drama. Since Aristotle, ${ }^{12}$ these emotions are largely based on a destabilizing moment entailing the discovery of a striking reversal of fortune, and are explicated predominantly through the plot, character, thought, and acting as constructive (cathartic) instruments, while spectacle and the larger setting receive far less attention. Even though access to a more genuine experience can be sought, as, for instance, through modes of performance where pain is 'incorporated', disrupting and reversing 'the familiar' as strategy inductive of confusion and anxiety, ${ }^{13}$ for the audience, operations of fear are largely confined to those theatrical moments where it remains external, attached to events representing reality and hypothetical characters. As such, emotion is established through recognition and relies on the more voluntary self-motivated instigative modes of intentionality and imaginative empathy.

The presence of non-mediated feelings that issue from the corporeality of theatre-as-event are acknowledged as pertinent to the practice of the performer in the phenomenon of 'stage fright', linked to anxiety embedded in the performative act and, more recently, also with regard to the audience, as the particular form of the emotions of 'embarrassment' 
London: Johns Hopkins University Press, 1988), pp. 131 ; in her profound cross-disciplinary work, Langer reconstructs the concept of feeling as a process (rather than as a product of some event), which as such entails vital activities of great complexity and high intensity, charting the entire domain bounded by the human body. She takes feeling in its broadest possible sense - whatever is felt in any way as sensory stimulus or inward tension, pain, emotion, or intent - to be the mark of mentality. This allows us to ascertain aspects of sensibility, awareness, excitement, or suffering as belonging to those events, and explicates how elaborate phenomena (ideas, images, fantasies) are rooted in the fabric of preconscious

processes. The distinction of two modes of feeling - that which originates from without, felt as impact and perceived as induced, and that which is felt as generating from within and more readily perceived as autogenic action ('subjective') - rests on how these are attained. Both embedded in the nature of vitality itself, these modes are seen in a continuously shifting transient relationship. The present study relies on these ideas for the conceptualization and exploration of affects of the site within a space-bodymind continuum. See also Martin Welton

'Once More with Feeling',

Performance Research, and 'shame'. ${ }^{14}$ Such 'discomforts' are modern phenomena, characterizing the contemporary theatre situation through practices and attitudes determined by socio-economic circumstances, and they belong to theatre to 'underpin' and 'undermine' its functioning as a mode of ethical and political communication. Actualized as psychological events arising at those moments of slippage during a play when the performance goes 'wrong', breaching codes and conventions, these emotional moments offer insight into the operations of theatre-as-event, presenting 'constitutive' possibilities within its 'failures'. ${ }^{15}$

Nevertheless, the absence of an account of the experience of theatre as a distinct spatial modality is a significant omission, considering that aside from drama, and aside from the 'apparent' anomalies and imperfections of contemporary theatre, the very possibility of fear becoming productive has been, all along, also firmly situated in the shared space of the theatre. Working from the premise that this situatedness is far from accidental, and that operations of fear might not be entirely elucidated in the above terms, this study proposes that an examination of experience and space discloses an under-explored dimension of fear in the theatre, where fear emerges from the effects of space and from the relations between bodies. The underlying claim here is that in the operations of the site, inherited from ritual in its constitution, ${ }^{16}$ residues of forms of knowledge of crisis, anxiety and fear can be traced through lived experience and enacted practices. ${ }^{17}$ These take on a distinct experiential form and, emerging through spatial mechanisms and circumstances, are inscribed as a permanent potential of theatre. This is to say that at the site, the operations of fear would include those measured and mediated forms deriving from the theatrical work, complemented by the psychological events that accompany live performance. Yet these are ultimately augmented, or perhaps inaugurated, by components of fear that are generated in/through space itself. Such components are subtle, but also immediate, latent and persistent. These components rely on corporeal engagement that short-circuits volition, and they proceed within a spacebody-mind continuum.

\section{Exposure - Accessing the Experiential Capacities of Space}

The operations of space can be addressed through its capacity to sustain a host of discrete processes and practices enacted at the micro level, centring on those clustered around the condition of exposure and dark space. Exposure does not only describe a circumstance of the stage/actor, but is conceived, asserted and confirmed as a generic property, and, coupled with dark space, is conceptualized so as to identify spatial principles and experiential charge. Exposure is a tool to re-articulate the site. The most 'dramatic' within a set of generic conditions, exposure is integral to theatre as a distinct mode of spatial organization. ${ }^{18}$ It is generic in that it partakes in the constitution of the event. It is intrinsic, designating major recurring features of a topological and morphological nature that underlie its principal effects. These features qualify space throughout and affect the minute situations of all participants involved. 
10.1 (April 2005), 100-13, for a discussion of feelings with respect to the creative work of the actor.

12. Aristotle, 'Poetics', in The Complete Works of Aristotle, ed. by Jonathan Barnes (Princeton, NJ: Princeton University Press, 1985), pp. 2316-40.

13. Kim Solga, 'Body Doubles, Babel's Voices: Katie Mitchell's Iphigenia at Aulis and the Theatre of Sacrifice', Contemporary Theatre Review, 18.2 (2008), 146-60.

14. Stephen Aaron, in Stage Fright: Its Role in Acting (Chicago and London: University of Chicago Press, 1986), identifies the sources of this phenomenon in the nature of acting. Employing psychological and psychoanalytical perspectives, he explicates stage fright through the emotive and mental conditions of vulnerability as linked up with issues of control and power. Nicholas Ridout, in Stage Fright, Animals, and Other Theatrical Problems (Cambridge and New York: Cambridge University Press, 2006), pp. $1-$ 95 , investigates conditions of discomfort as associated with the performer-audience encounter, drawing on philosophical thought and theatre criticism around the concept of 'theatricality'. $\mathrm{He}$ theorizes such phenomena in the context of theatre in modernity, emphasizing
As such, exposure is traceable within the various spaces in which theatre takes place: theatres 'inherited' from different historical periods, distant as well as recent; theatres established in 'found' spaces (warehouses, factories, salons), 'adapted' permanently or temporarily, employing fixed or flexible schemes. As diverse as these spaces may be, they nevertheless can be seen as actualizations of the theatre mode, explored in terms of the generic qualities they hold in common, and rendered through exposure.

Yet, furthermore, examining the site through the concept of exposure would be to disclose a form of experience, which thrives on ambiguity, reverberates with structures of fear (patterns of circumstances and symptoms), reproduces fear-related components (vulnerability, anxiety/ stage fright), entails activated states and engagement with something unknown, and is, hence, performative ${ }^{19}$ in nature. This is to say that there is an 'uncanny' side to the site (where 'uncanny' is taken in the sense of the 'unfamiliar' as 'un-recognized', but also as denoting those parameters of space that are artfully and subtly disconcerting), the exploration of which might generate grounds for a reassessment of concerns with space in the context of performance. This reassessment suggests that exposure as a form of experience is integral to the performative process (connoting in this a complex compound evolving through and incorporating diverse experiential layers, each in its terms holding potential for change), and helps to acknowledge the site as a corporeal component of theatrical praxis (referring to praxis as multidimensional actualization of the broadest ontological functions of theatre).

\section{Theoretical Contexts}

\section{Site and Scene in Discourse and Practice}

A survey of the major contexts that centre on space, experience and the body - theatre/performance studies and architecture - confirms that the experiential capacities of space are firmly attached to the presentation/ perception framework of the theatrical event. In both contexts, the construction of theatrical meaning in space is informed by an inherent dichotomy: 'space as a medium of representation' and 'space as physical place'. The main aspect for study of physical space is situated in the relations between the stage (practitioner space) and the auditorium (audience space) as components of the 'divided yet unitary' 'theatre space, ${ }^{20}$ seen at the core of the experience of theatre. Thus, in architecture, these two spatial components are explored as permanent configurations, whereas in theatre studies they gain importance with regard to their possible temporary re-definitions. Nevertheless, both theoretical contexts emphasize the radically different characteristics of these spatial entities, which is to say that operations of space are seen in explicitly different terms for the two groups involved in the theatrical situation.

In theatre studies such distinctions are correlated with the roles of producers or participants in the process of meaning formation. Hence, 
especially those social, economic and political powers pertinent to capitalist growth which shape the urban condition and mentality, as well as theatre in terms of the pervasive division of work and leisure. Hence these phenomena, though bearing a situational dimension, are explicated rather in terms of the ethics and politics of performance. Concurring on the relevance of an inquiry on fear to the understanding of theatrical practice, the present study focuses particularly on the spatial circumstances and mechanisms whereby components of fear would be mobilized, seeking to highlight such operations in the condition of 'exposure'.

15. Ibid., pp. 1-34.

16. James Madge, in 'Type at the Origin of Architectural Form', Journal of

Architecture, 12.1

(Winter 2007), 1-35 Exploring

developments in the formulation of the architectural space of theatre in the western tradition, Madge asserts that theatre as a type - armature entails combinations of properties that remain invariant, independent of any change in the patterns of functions ascribed to such properties. Hence theatre, in spite of major transformations, does reproduce the five constitutive elements of the ritual site of the cult of Dionysus - the megaron shrine, the open space enclosed by a wall and an altar, and the banked while space in its immediacy appears increasingly pertinent to the experience of the performer, who works upon and 'energizes' it, the principal characteristic of the experience of the theatrical for the audience emerges from the artificiality borne in the juxtaposition of the physical reality of the stage and the 'fictional' - 'dramatic' or metaphoric - created there in and through space. ${ }^{21}$ Space, then, is assigned a major function in maintaining the double awareness of reality/non-reality, ${ }^{22}$ while 'present-ness ${ }^{23}$ in the experience of theatre audiences is accounted for as that which is being produced in the actor-audience relationship and hence revolves around the theatrical work. Seen in these terms, experience inevitably emanates from the action on stage and, in perspectives emphasizing 'the act and nature of viewing' as the channel of reception, ${ }^{24}$ the exploration of the effects of space is confined to the visual codes of the scene. Even in broader perspectives relating to a range of theatre cultures and practices and accounting for the-play-as-event rooted in bodies and environments, the key issue of inquiry is how space could be made to corroborate with the event. ${ }^{25}$ Hence, though theatre space is shared and attains explicitly corporeal dimensions (tactile, and acoustic qualities, volume, character), these dimensions take the form of 'predetermined theatrical' meanings within distinct 'architectural realities'. A vital concern for contemporary theatre is to explore how such 'spatial machines' would partake in the 'unique expressions of cultural statements ${ }^{26}$ that are formulated in the stage-auditorium interface.

In theatre practice the attempt to affect audiences through space is attributed to the construction of stage space through the conventions of dramaturgy, directing and scenography. This takes the form of temporary manipulations through which 'dramatic space' is moulded and cast upon the physicality of the scene. This is to say that affects are sought and produced in reference to, and for the duration of, a particular performance.

In the corresponding branch of the field of architecture, theatre is taken to connote a particular type of building where space exists to accommodate performances, rather than to incite experience. One line of architectural research engages in substantiating guidelines for design, depicting essential functional/spatial components and their spatial organization and configuration in terms of possible implications for relations and activity patterns. ${ }^{27}$ In a venue resisting a modernist emphasis on functionality, a range of studies aims to understand theatre space by assessing effects of architectural character in historical examples, where the theatre building is conceived as a cultural manifestation and text to be deciphered. ${ }^{28}$ More properly experiencebased approaches emphasize the boundary as the particularly architectural problem, and explore its effects in terms of the distinction between the protected autonomous microcosm of theatre and its exterior, which sets it within a cultural context. Analysing major models of the western tradition as formalizations of distinct theatre practices, and contemporary realizations through the principles and/or concepts of their design, these suggest how specifically articulated architectural space would influence the overall experience of theatre. ${ }^{29}$ The issue of how architectural presence might support an 
seating bounding it on the other side. The three distinct evolutionary histories of theatre, all utilizing a different potential borne by this constitutive logical principle, are grounded in the changing notion of 'essence' of theatre emphasis falling respectively on the figure of seating, on the cavea - the space of theatrical action (orchestra/stage), or on the shrine (the 'miracle' box stage) where, behind the proscenium arch, space is 'lavishly furnished' to animate performance.

17. Richard Schechner, The Future of Ritual: Writings on Culture and Performance

London and New York: Routledge, 1993), pp. 1-23, 228-65. Schechner brings forth the harnessing of violence and fear as a major function of ritual, to be collectively achieved. While ritual-based aspects of fear are traced to the context of various contemporary mass events, and explored regarding all participants, regarding theatre they are specified within the practice of performers.

Nevertheless, these offer grounds to perceive, and expand on the possibility of analogous formations of fear in terms of their spatial constitution, throughout the site and concerning all involved in the theatrical situation.

18. For a

conceptualization of the site in terms of a broader set of such authentic theatrical experience is extended in a discussion of diverse cases based on an analysis of the playhouse as a prototype. This enhances awareness of the architectural nature of 'recurring family characteristics' and allows an understanding of space as it shapes the relations among participants in terms of kinds and intensities of contact. Hence physical space, densely packed, emerges as a valid source for the actor's prospect of response, and for the audiences' prospect of mutual influence, demonstrating the implications of architectural design (form, sectional treatment, boundary articulation, distance)..$^{30}$

While such approaches help conceive of a 'function' of space, which exceeds that of a 'setting', as being to accommodate the experience of performance through permanent particularly architectural means, contemporary architectural practice tends rather to follow the scopic conventions set by the 'theatron' (originally a place for viewing, seeing) in configuring the site. Yet the terms of audio-visual comfort do not qualify space in any other way; they stop short of accessing any experiential bearing that might issue from the very circumstance of visibility, or of addressing any of the special, even fear-related effects to which it may build up within different spatial formations. Such terms, evidently, require further particularization.

\section{A Detour - on Fear through Space}

Fear and space appear to be more directly co-relatable in perspectives outside the discourse on theatre. Outside even the discourse on space, the cases of claustrophobia and agoraphobia exemplify connections between anxiety and the effects of extreme or excessive spatial factors that are hard to tolerate: tight enclosure for the former, vast and uncontrollable space and crowdedness for the latter. ${ }^{31}$ At the other extreme, in Burke's philosophical thought, it is the 'great', which appears in a striking bond with the 'terrible'; fear participates in the encounter with the 'sublime' by way of the utmost dramatic conditions of 'solitude', 'silence', 'vacuity' and 'darkness'. ${ }^{32}$ It can be perceived that an explicit spatial dimension would underlie the experience of each condition in question.

Indeed, it is especially the context of the sacred, where the architectural monument - intended as a physical manifestation of the sublime and hence operating through the extraordinary - would bring forth the possibility of space as source of experience. ${ }^{33}$ These 'ritualarchitectural events' present a mode of instigation, which is immediate and proceeds through formal properties. This perspective considers space as it influences dispositions, yet would, provided the circumstances, also elicit emotive response to the extent of inflicting different kinds of fears: it would shock, crush, engender awe, intimidate, evoke the sense of inferiority, or inadequacy. ${ }^{34}$ These would be triggered through excessive and hence rather unique spatial effects and provocative exaggerations of particular features: sheer size, highly formalized hierarchical order, peculiar articulation of volumetric form or architectural components and ornamentation. Hence such space-generated fears, though in their 
generic properties, see Maya

Nanitchkova Öztürk, 'Through the Body: Corporeality and Consciousness at the Performance Site', in Consciousness, Theatre, Literature and the Arts, ed. by Daniel MeyerDinkgrafe

(Newcastle: Cambridge Scholars Press, 2006), pp 143-58.

19. Rather than 'iteration' or 'enactment' as notions frequently attached to the performative in the context of theatre, this author adheres to a more general interpretation, which relates and emphasizes the performative as 'doing', as being nontextual, irretrievable, contingent, spontaneous, immediate, indeterminate, excessive and affective (John-David

Dewsbury,

'Performativity and the Event: Enacting a Philosophy of Difference',

Environment and Planning D: Society and Space 18 [2000], 473-97). Exploring the premise that experience generated by space itself, through the body, has inherently the nature of an encounter

(connoting a meeting between two entities that is essentially unmediated, spontaneous and preintellectual, and that instigates a confrontation with something unexpected, and that involves elements of disclosure), and substantiates such links of space to the performative. moderate form involving challenge and stimulation as elements of 'productive anxiety', ${ }^{35}$ would ultimately entail an act of direct engagement and contemplation of space itself, 36 occupying experience in full.

In contrast, the 'uncanny' comes forth as a possible experiential dimension: a mental state of projection, that would arise within any architectural space, provided that space allows a slippage 'between what seems entirely homely and what is definitely un-homely, ${ }^{37}$ a slippage 'between waking and dreaming ${ }^{38}$ by way of eroding the boundaries between real and unreal. This perspective discloses a different aspect of space-related fear and estrangement: an unsettling quality that is strategically embedded in contemporary architecture through practices relying on subtle deception of visual perception, on generating illusionary spaces by blurring boundaries, mirroring, or artful manipulation of light. At the level of the architectural object and the urban this entails the employment of 'fragmented forms mimetic of dismembered bodies', buildings 'lost in mirror reflection', 'seeing walls' simulating transparency. ${ }^{39}$

Evidently while each of the above perspectives offers insight into the possible constitution of particular space-related fears, none of these fears appears directly applicable or relevant to theatre space. Nevertheless, while these perspectives have helped to set fear in a spatial context, the notion of the 'uncanny' has indicated a 'peculiar kind of fear' positioned between real terror and faint anxiety, while the fear component has been indicated as productive, not only in that it activates, but also in that it is linked to the attainment of the 'sublime'.

\section{A Conceptual Framework}

\section{Deriving Referents - on Structures of Fear}

For this study, instead of particular kinds of fear, it is rather the structures of fear that are of interest, that are recognizable in terms of patterns of interrelations between pre-conditions, constituents (and/or processes at the micro level), and affects, and therefore help to understand space as it induces and carries them through. Hence, based on diverse perspectives on fear, ${ }^{40}$ a set of circumstances, symptoms, and components pertinent to fear are proposed as referents, so as to restore the interpretative capacities of exposure, and, ultimately, to allow for the recognition of possible residues at the site.

Fear - 'the strongest emotion which the mind is capable of feeling, ${ }^{41}$ is conditioned and arises within a dangerous situation bearing an external or internal threat, perceived as such because it would entail ambiguous components to which adequate reaction appears impossible. Fear enters and overwhelms at times of doubt and uncertainty and, in triggering confusion and even shock, further amplifies destabilization. It expresses itself as an acute tension between disconcerted excitement and temporary immobilization (lack of decisive action): through the symptoms of anxiety, whereby fear actually forewarns. 'Signal' anxiety is born of a moment of sudden encounter, a situation that is essentially 'open' in that 
20. The terminology employed here follows that introduced by McAuley, Space in Performance.

21. Ibid., p. 23.

22. Ibid., p. 41.

23. Ibid., p. 117.

24. Susan Bennett, Theatre Audiences. A Theory of Production and Reception (London and New York: Routledge, 1990), p. 72.

25. Wiles, in A Short History, discusses different types within the western theatre tradition in the light of evolving conceptions of space and self, and, relying on Lefebvre's framework, as produced through and for particular socio-spatial practices. With regard to Foucault's tripartite history of space, various spatial forms are accounted for in terms of subsequent notions of theatre, such as 'space of emplacement', 'space of extension' and 'the modern site'. While each may contain traces of previous forms, these are affirmed as to the special spatial potential they present in formulating theatrical meanings. In this, 'the site' whose spatiality is seen as defined only by its relationships would best lend itself as a 'counter-site' (based on the concept of 'heterotopia'), to speak about 'other' sites that 'represent, contest and invert other spaces in society'. it holds no predictable outcome, but also in that it demands engagement and hence orients outwards. Frequently reported as linked to a neitherthis-nor-that-situation, anxiety is characterized by a building up of tense apprehension and autonomic arousal. In this interval of hesitancy, of being stopped short of a meaningful response, these energies are inevitably constrained. Yet it appears to be precisely this lapse which presents both the most malignant and the most productive aspects of anxiety. As utter agitation, it is apt to bring latent preconscious fear to consciousness. Yet, also rooted within the emotional turmoil and destabilization, it challenges and, by upsetting habitual patterns, liberates, demanding original approaches and resourceful solutions; it is conducive of creative improvisation and, hence, emerges as a state that is rather potent and unpredictable.

\section{Exposure - Conceptual Implications versus Scopic Conventions}

In conventional usage, exposure is employed as a spatial term firmly attached to the performer, the act, and-by extension-the stage. The fact that the theatre provides the principal setting for one of its meanings - namely 'frequent appearance before the public'42 — prompts its use within the limits of this appointed sense, and supports the preconception that exposure exclusively applies to the situation of the performer. As presentation relies on placing that-which-is-performed in such a way as to facilitate its observation by a large number of onlookers, exposure is taken to describe the situatedness of the stage with regards to the auditorium, and to account for the spatial circumstance of openness (as lack of obstruction) and visibility.

Only occasionally is it used in the sense of an experientially consequential condition, linked to the state of 'stage fright' - again pertinent to the actor. ${ }^{43}$ In this, the major effect of exposure is seen in the 'standing alone in front of thousands of strangers', ${ }^{44}$ as the explicit circumstance of visibility on stage. This is to say that the capacity of exposure to affect is recognized insofar as it enhances the actor's fear of unmasking, of the audience seeing 'something it is not supposed to see, namely, his fear'. ${ }^{45}$ Such affects are foregrounded by the psychic strain over the role that the actor assumes, and are interpreted with reference to the performative act. Hence in these interpretations, possibilities, such as the fact that exposure might be affecting the entire site, that it might be operating through various mechanisms, or that it might be employed to disclose other disturbing bearings of this condition, remain obscured.

Relying precisely on these premises, this article attempts a reconstruction of exposure as an analytical and interpretative tool to rearticulate the site, and experience, by way of exploring its implications. Examining exposure within the context of its diverse connotations helps to conceive its ability to designate particular conditions of a spatial nature, while at the same time posing these conditions as a mode of being, providing access to a relatively stable core of possible effects. Exposure denotes a distinct way of occupying space and comes to signify this condition in terms of the principal means, the specific spatial 
26. Ibid., pp. 1-22, 24066.

27. For instance, Ian Appleton, Buildings for the Performing Arts: A Design and Development Guide (Boston:

Butterworth Architecture, 1996), and Michael Forsyth, Auditoria: Designing for the Performing

Arts (London: Mitchell, 1987).

28. For further inquiry on this aspect, refer to Marvin Carlson, Places of Performance: The Semiotics of Theatre Architecture (Ithaca, NY and London: Cornell University Press, 1989). In his perspective, the theatre building is interpreted as to the meanings it conveys through its architectural vocabulary: location within the city and correlations to other urban elements, volumetric composition, arrangement and articulation of relations between spatial components, physical appearance, and structural and decorative elements.

29. Gaelle Breton, Theaters (New York: Princeton Architectural Press, 1989).

30. Iain Mackintosh, Architecture, Actor and Audience (London and New York: Routledge, 1993), pp. 1-25, 154-75.

31. For a psychiatric and psychological perspective on these, refer to Richard S. Hallam, Anxiety: Psychological mechanisms, through which it is achieved. It, moreover, characterizes a way of being in space - namely, within the perception of a correlation to something else. Along with these, and even with regard to its most straightforward meanings, exposure also qualifies this 'way of being' as a condition not entirely innocuous, where uncertainty, or even risk, comprised of fear-related ingredients, inevitably intertwine. Hence, while it is taken to describe a location with regard to some major powers (the elements, forces, onlookers/observers), it comes to suggest possibly harmful influence. When it designates a situation that 'allows one to be seen', it implies that this situation is enforced in such a way as to 'exhibit' and 'display'; it is subject to a gaze.

Obviously exposure conveys a kind of accessibility beyond visibility in that it operates through more profoundly physical as well as affective mechanisms. These entail a 'laying open' that is carried out in such a way as to invoke submission, stirring up a sense of 'being in an unprotected place', a potential 'subject to influence or action', hazardously disclosed, palpably bare. Exposure imparts a sense of lack - of obstruction, protection, or defence, to insinuate the possibility of intrusion inspection, judgement, ridicule, attack. It thereby renders the spectator or performer vulnerable with regard to something in excess, overwhelming, or unpredictable. These suggest that it would be essentially the feeling of being prone to some special manipulation through space, and under the effect of relations of a certain kind, which would account for its 'uncanny' charges.

Further interrogation of the etymology of the word expose helps to detect its suggestion of physical terms, as dynamic impulses or shifts, paired with compulsion. The prefix $e x$ - itself upholds two suggestions: in the sense of 'without', it denotes stasis, while in the sense of 'out of', 'free of', it indicates motion - direction away from and change with respect to a condition previously held. In turn, pose as 'placement' conveys constraint in that one is being firmly situated within specific circumstances and relations. Thus, in the 'presenting of one to another', exposure is actualized as a putting forth and out of position. Pertaining to both a placement (being kept, held, at rest, arrested) and a displacement (a forceful alteration of a former, accustomed, protected circumstance), exposure can be conceived as a physical condition essentially ambivalent, and hence labile.

Exposure bears still more deeply affective ambiguities that resolutely point to components of fear ingrained in this condition. Thus, while in special cases the relations between the parties might be controlled, the spatial situation itself does not hold a 'direction' that would appoint one of the parties as 'the exposed': the 'presenting' in question is bound to turn out inevitably, and decisively, reciprocal. The repercussions of exposure are that it collapses distinctions between observer and observed, intruder and intruded, subjecting participants to the possibility of a perpetual and haphazard oscillation between two polar opposites, two experientially inverse conditions.

Furthermore, as this sense seems to rely primarily on the distinction of the location of the 'exposed' with respect to its immediate environs, it 
Perspectives on Panic and Agoraphobia

(London and New

York: Academic

Press, 1985), pp. 1-

11, 115-33. For a

sociological

grounding of

agoraphobia, refer to

Georg Simmel's essay

'The Metropolis and

Mental Life', in $O n$

Individuality and

Social Forms, ed. by

Donald N. Levine

(Chicago and

London: University

of Chicago Press,

1971), pp. 324-40.

32. Edmund Burke, $A$ Philosophical Enquiry into the Origin of our Ideas on the Sublime and the Beautiful

(Oxford: Basil

Blackwell, 1987), pp.

57-87, 129-60.

33. See Lindsey Jones,

The Hermeneutics of

Sacred Architecture,

Experience,

Interpretation,

Comparison. Vol. 2:

Hermeneutical

Calisthenics:

Morphology of Ritual

Architectural

Priorities

(Cambridge, MA:

Harvard University

Press, 2000). This

cross-cultural study

presents an

interpretation of

sacred space from a

hermeneutic

perspective, where

'built ritual contexts', connoting

architectural space in

close correspondence

to ritual functions,

are explored as to the

spatial strategies

through which a

'double mediation'

('engage' and

'enliven') is

actualized, wherein

the potentials of

space for

'productivity' and

'transformation' are seen to lie.

34. Ibid., pp. 129-52. becomes apparent that it would be possible to instigate the sense of 'being exposed' even without a 'visible' counterpart. Such distinction, explicitly executed, would suffice to invoke an 'other' to which a particular location correlates. Surely this aspect of exposure articulates 'internal' mechanisms at work, such as a liability of conflating perception with apprehension. Exposure exerts its most vicious aspects under circumstances that impair the sense of control, or vision: circumstances of expanse of space, blurring, concealing, or manipulation of light that is blinding either in its brightness or in its absence. In relation to this latter circumstance, it is possible to perceive aspects of exposure ingrained in the experience of darkness, though with regard to vision they appear as contrary circumstances. Ultimately it is precisely thus - by insinuating a felt-but-unknown - that exposure subjects one to a dual deprivation: it obstructs the perception of an actual relation, as well holds short of conceiving of a meaningful response.

Darkness, too, is a circumstance, whose deep, shadowy side has remained largely hidden, though dimming the lights is a means frequently accompanying performance, employed to focus attention on the action on stage. Only exceptionally, as in certain unconventional performances, is it utilized, and discussed, in its capacity to deter the primacy of vision and provide an opportunity to re-attain sense and emotion on various other levels. ${ }^{46}$ Given some other sensory input, it is seen as an effective means to stimulate, perhaps even help reactivate precisely such 'other' channels of sensing physical reality. Nevertheless, in spite of their otherwise insightful argumentation on dark space, such discussions tend to avoid its more far-reaching disconcerting aspects.

Yet dark space, conceived as one of the 'great privations', ${ }^{4}$ has underpinnings of fear. Considering its capacity to impair the visual perception of both spatial boundaries and things in space, dark space actualizes, by itself, a fundamental circumstance that embodies three of these privations at once (involving 'vacuity' and 'solitude'). Furthermore, it can be established that dark space obstructs essential processes of consciousness by undermining the possibility of the self to engage with space and attain awareness over its precise location, or even its own borders, to the extent of effectively deteriorating the sense of physicality. ${ }^{48}$ Dark space succeeds in imparting a vibrant limitless void that is experienced as matter, touching, enveloping, even permeating the body, and thus invokes an 'imminent': the possibility of danger.

\section{Topological Instantiations}

\section{Theatre Spaces - Seen through 'Exposure'}

This above conceptualization of exposure not only reconstructs its interpretative capacities, it also demonstrates how exposure inherently pertains to the site: arising from within its fundamental spatial structure and form, and designating major recurring features and the underlying 
35. Ibid., pp. 90-94.

36. Ibid., pp. 213-33.

37. Anthony Vidler, The Architectural Uncanny: Essays in the Modern Unhomely (Cambridge, MA and London: MIT Press, 1992), p. xi. Vidler develops an in-depth theorization of architecture in the context of critical theories on modern estrangement. He reveals architecture as a manifestation, both literal and metaphoric, of the un-homely, expressing an aesthetic sensibility derived from the negative dialectics of the modernist avantgarde. For this present study, which focuses on capacities of physical space with respect to immediate experience, rather than on the cumulative one that acknowledges the architectural object/ building or the urban in their totality, it is the notion of the 'uncanny', as a special kind of fear midway between potential and actualization, as well as the notion of 'framing', that have been particularly informative.

38. Ibid., p. 11.

39. Ibid., pp. ix-xv.

40. See Burke, $A$ Philosophical Enquiry, a seminal work showing dimensions of fear to underlie some of the modes to the attainment of the sublime; Verena Kast, 'Angst und

Faszination.

Emotionen in Bezug auf das Fremde', in Das Eigene und das Fremde (Solothurn principal effects of space. Precisely because of such an aptitude exposure, when employed as an analytical tool it helps to render the operations of the site in constituting the performative event, as well as to articulate 'dramatize' - architectural space with respect to experience. This foregrounds the common aspects of the considerable diversity of theatres in which contemporary performance practices take place. Indeed, though theatre spaces emerge within their specific historical time, constructed through and expressive of specific socio-cultural relations and incorporating different principles of theatre production, ${ }^{49}$ in terms of their principal spatial constitution they reproduce the relations embedded in the theatre mode of spatial organization. Exposure emerges as a generic principle, where the properties of physical space that enable the event intrinsically cohere with the particular spatial circumstances and mechanisms of exposure.

Recognized as a condition of exposure in that it relies on the distinction and/or containment of a centre, this mode underlies all three 'fundamental theatre forms': ${ }^{50}$ the deep proscenium, the open thrust stage, and the full arena. Hence, while each particular theatre space in its entirety might come forth as a unique amalgam, the major effects arise through the correlation of any one of these theatre forms and the principal traits of the architectural space in which they are actualized. It can be argued that this mode, and the principles of exposure, would be legible, and operational, in each case: in theatres constructed within a uniform prismatic volume (such as the workshop, studio, laboratory, (black box'), as well as in those where the relations of stage and auditorium are structured in composite spaces. Thus, in the Italian prototype, the theatre mode is articulated through the spatial segregation between the deep box stage (equipped with complex technology) and the cylindrical auditorium formed through several superimposed rows of boxes. Its French adaptations differ in that they include the orchestra and stage floor with seating alongside, while raked tiers in the back suggest a more fluent transition to the galleries. Its English variants take circular or polygonal forms, and retain the Elizabethan open court in their scheme, where the apron stage or thrust stage extends into the centre of the auditorium to be almost surrounded by the stalls of tiers and side walls. More recent (modernist) examples feature homogeneous convertible spaces allowing for rearrangements and/or subdivision, with flat or amphitheatrical seating instead of the box system. In all these cases, the principal operation of space with regard to 'performance as presentation' can be examined through exposure, and explicated in terms of its specified effects.

Furthermore, exposure exceeds these aspects of the generic. By marking essential distinctions between the circumstance of 'being visible' and the conditions of 'being exposed', exposure reveals the spatial logic of the entire site. It can be ascertained as generic in that it unveils a range of characteristics that qualify space and specify a mode of being regarding all participants involved. Exposure is 'sensed', viscerally felt, constructed through properties of physical space that are also tactile, even haptic in nature, and proceeds, as much, through and in terms of the body. As such, this suggests that not only the bodies of performers, ${ }^{51}$ but also 
und Dusseldorf:

Walter-Verlag,

1994), pp. 214-38, a

study on the links

between fascination

and fear in terms of

possibilities for

personal

development;

Hallam, Anxiety,

discussing

generalized anxiety

syndrome; and

Sigmund Freud, $A n$

Outline of

Psychoanalysis, trans.

by James Strachey

(New York: W.W.

Norton, 1949), pp

13-45, providing a

conception on the

operation of, and

links between,

different levels of

consciousness.

41. Burke, $A$

Philosophical Enquiry, p. 39.

42. The following

conceptualization is

based on the

meanings of

'exposure' and

related terms

provided in Webster's

New World

Dictionary, 2nd

college ed. (New

York: Simon and

Schuster, 1980).

43. Aaron, in Stage Fright, discusses the emotive impact of stage fright in terms of the distinctions between 'signal' and 'traumatic' anxiety, associating it more tightly with the latter. He points to the psychic origins of its destructive effects in the inner suppression of defense mechanisms, and assigns to exposure the status of but one of various factors that enhance this notorious state. Ridout, in Stage Fright, pp. 35-69, explores this phenomenon as anxiety integral to those of members of the audience would assume an alert and active status, registering the specifics of their circumstances, ${ }^{52}$ and acknowledging their condition. As such, exposure can be employed to rearticulate the site in terms of the prevailing morphological and topological features, effective throughout. Such a rendition of different configurations opens up the opportunity to complement interpretations in terms of a variety of experiential characteristics (communication of theatrical meanings, intensity of performer-audience relation, complicity) with a model that augments reverberations among spatial circumstances, experiential components, and structures of fear.

\section{Revisiting Site-specific Actualizations}

In contrast to views on theatre space as an inert physical framework, 'dramatized' through exposure, the site emerges as an engaging material substance charged with, and operating through, dynamic impulses and tensions. The feel of being prone to some special manipulation through space is made palpable, inscribed in architectural form at various levels: engendered through the dynamics borne in the spatial constitution of stage and auditorium, through the constriction of emplacement, through the subjection to encounter, at times unexpected, all building up to its destabilizing - and even artfully disconcerting - 'uncanny' effects.

Thus, articulations of the stage in built form can be understood in terms of the spatial logic of exposure, where forces pertinent to its mechanisms are being augmented, and become effective throughout. For the stage is rarely simply there; it is presented, and made to perform by extending its physical space and enlarging its field of influence. When it is instated as a node, configuring the rows of seats in tight correlation, it is forces of attraction that are being rendered in physical form, and hence also amplified - effects perceivable even when the stage is set within spaces with flat floor (a staging form frequently employed in smaller-scale studio theatres with less equipment). In the case of the full arena type of stage surrounded by seating, it acts as the centre of such forces, and appears powerful, balanced and devoid of horizontal pressure. Nevertheless, even the simplest means of sectional distinction, such as 'sinking' the stage regarding the auditorium, is apt to produce its specific dynamic impact, enhancing centripetal forces in submitting the stage to observation. In cases where the stage is disclosed by an elevating push imbued with the power to impress the act into space, the principal 'gravitational' dynamic of such configurations is rendered controversial, as both impulses are explicitly maintained in physical space.

The proscenium theatre form, too, presents a special case of mobilizing ambiguous conditions. The circumstance that the box stage offers only one interface with the auditorium and restricts certain aspects of exposure is enhanced by the decisive separation of the proscenium arch. ${ }^{53}$ Yet this tendency is also counteracted: this stage is at the same time quite effective as an absorbing void, a funnel, framing attention. Actualizations of the thrust stage make palpable the forces of a launching motion forward 
the profession of the actor, in reference to a theatre industry characterized by tough competitiveness and socio-cultural conditions blurring distinctions amongst realms of existence (privacy in public). Anxiety is enhanced, as exploiting private experiences to 'move'

entertainment consumers is an expected and frequently implemented practice. Though spatiality is not a central issue in these accounts of stage fright, for this present study they provide grounds to infer certain links between circumstances and symptoms of exposure, with extensive documentary material available, especially in the former source. However, exposure is conceived as a condition that triggers such states in the first place, and its tight correlation with stage fright is shown in

demonstrating exposure as a property consequential for all participants involved.

44. Aaron, Stage Fright, p. 65 .

45. Ibid., p. 59.

46. Welton, in 'Once More with Feeling', discusses darkness as a medium of performance in its potential to enhance awareness over 'sound', 'touch' and 'feeling' with regard to the experience of both actors and participators. towards the auditorium and a vigorous intrusion into it. Such impact can be further specified, considering how different formal and sectional constitutions of the stage work dynamically. Thus the raked or modular thrust stage tends to generate an impetus akin to that of an amphitheatre, which, mobilized in an opposite direction, shifts and compresses space towards the auditorium.

Such rendition can be extended to involve in more detail various possible modifications of these principal forms and to point to their specific effects, such as, for instance, the effect of an apron stage that projects forward and reasserts it also as a node within the auditorium, while an orchestra pit - a spatial interruption - would emphasize the isolation of the stage. Nevertheless, even limited to such principal cases, this perspective not only explicates the role of space in constituting 'performance as presentation' through various mechanisms and specified effects of exposure, it also allows recognition of the essentially animating impact of these mechanisms throughout, charging space and mediating the sense of tension between actual situatedness and experienced volatility.

Yet exposure is not reserved solely for the purpose of 'presenting' an act on stage. Formulations of the auditorium are, in addition specific actualizations of its mechanisms and circumstances, and as such do participate in forming the dynamic character of the site, frequently adding ambiguity to overall effects. Even a simple straightrow flat-floor face-to-face arrangement actually ensures that the auditorium confronts the stage and is analogously displayed. In terms of configuration, the cases where the auditorium is made to converge towards the place of action univocally express the alluring power of the centre by focusing around the arena stage, while making this confrontation more palpable by contradicting the horizontal impact of the thrust stage. A different set of forces is mobilized through sectional treatment, in cases where the auditorium is manifestly presented by way of a steep incline, by the jutting out of the balconies (frequently employed in contemporary theatres), or through the vertical drive of tiers (gallery or box systems alike). The uprooting momentum of these spatial forms is, then, enforced by the sweep of the confinement of a boundary that presses in. These interact, or interfere with the effects of different configurations, mediating the sense of exposure as a physically ambivalent condition.

Furthermore, the affective nature of circumstances of exposure derives from the fact that its principles are executed in strict geometrical discipline (legible primary form, axial alignment of spatial components, symmetrical configuration), where adjusting the spatial components in tight, formatted interdependence comes forth as one explicit physical manifestation of the compulsory traits of exposure. These help explicate the peculiar intensity with which the principal relations - between performers on stage and participators in the auditorium - are perceived. Hence, while the case of the full thrust stage set within the playhouse is seen to materialize these relations at their most 'direct', ${ }^{54}$ the affective power of this spatial form can be understood in that it also is paradigmatic of exposure between the two parties involved. 
47. Burke, $A$ Philosophical Enquiry, p. 71.

48. For a more detailed discussion on aspects of dark space, refer to Vidler, The Architectural Uncanny, pp. 16775 .

49. This brief review of theatre spaces is based on descriptions provided in the works of Breton, Theatres, pp. 4-13, and Wiles, A Short History.

50. Wiles, A Short History, p. 247.

51. It should be noted that 'the body' of the actor is being increasingly acknowledged, constituting the major tool for performance, energizing space. See McAuley, Space in Performance, pp. 90 125.

52. For a substantiation of the role of the senses in bodyenvironment relations, refer to James J. Gibson, The Senses Considered as Perceptual Systems (Westport, CT: Greenwood Press, 1983), pp. 1-58, 97 135. His argumentation allows conceiving of the body as engaged in an active exploration through various perceptual systems, and, for the present study, it has offered grounds to interpret space especially with respect to the operations of the haptic.

53. Wiles, A Short History, p. 238, observes that the proscenium arch, for some time rejected as
Among these manifold actualizations, the amphitheatre - evocative of the austere space of the steep and confined hemicycle of the ancient Greek model-is paradigmatic of the more controversial and ambiguous aspects of the spatiality of exposure. There, several of its mechanisms operate with acute precision and economy through the curved slope, which sets the semicircular or polygonal seating, but also forms and almost encloses the space. Hence, while it mediates a forceful focusing impetus, the amphitheatre in its fan-like spread around at the same time augments the sense of being unequivocally exhibited, held fixed in space ${ }^{55}$ Furthermore, in re-establishing spatial continuity with the stage and within the auditorium, it enforces awareness of all those involved in the situation.

Evidently, while the sense of exposure requires distinction from its environs, it is also bound to the factor of spatial continuity. Hence, in certain types of composite theatre spaces perception among spatial units would be substantially impaired, such as that among deep overhanging balconies or galleries, reducing effects that arise from the diversity of relations. Nevertheless, those structured spaces in particular where each spatial component works with its explicit dynamic character present perhaps a special potential as to the affective power of exposure: they allow 'constructing' spatial uncertainty, for the inserting of controversial impulses, for proposing of layers of space with divergent impetus. Hence, certain architectural interventions would 're-incorporate' the stage within a space that still keeps its structured, even subdivided character, such as when a proscenium is reconfigured as a thrust stage, or when the stage frame in frontal auditoria is removed. Such re-integration, when approached by installing suspended overheads or screens in appropriate places, presents also a strong technique in amplifying ambiguity: it suggests a partial enclosure that pulls stage and auditorium together to the effect of diversifying the traits of the primary spatial form.

Within the auditorium, the effects of spatial segregation are toned down by galleries that are shallow, and in such cases even details like the use of perceptually permeable railings (lightweight and/or transparent materials) suffice to contradict compartmentalization and undermine the circumstance of safe repose. Another factor in the sense of exposure is the density of spatial effects, which is influenced by the size of space. While still operating in large spaces, such as in the theatres of the Italian or Elizabethan type or their extensive multifunctional contemporary counterparts, the sense of exposure is perceived more intensely in intimate spaces, such as those of Restoration theatres, of the small-scale new theatres in 'found' spaces, or of studio theatres, where its circumstances and mechanisms are tangible.

Strictly configured through the circumstances of exposure, the relations between performers and audience, along with their appointed purpose to increase attention over the action on stage, have the effect of charging the 'in between' and experientially contracting space. They not only consolidate the uprooting effects of the site, but are also resolutely reciprocal. Thus, the operations of exposure at the site, along with its more obvious effects, illuminate the actualization of those rather intricate and profuse conditions that trigger disquieting, unsettling, even alarming 
outmoded, is being rediscovered as the most 'theatrical' space available, in that it resists transformation into mere spectacle, and also in that the frame offers a tool to 'problematize' relations between viewing and viewed.

54. Mackintosh, Architecture, pp. 9$25,126-42$.

55. The assertion that the amphitheatre actually ensures a 'reverse' presentation to someone occupying the focal point can be supported by calling to mind how persistently it has been employed as a figure of the knowledge presented to the mind, receiving its physical expression in the memory theatre of Giulio Camillo. For more detail on memory theatres, refer to Frances A. Yates, The Art of Memory

(Harmondsworth and Ringwood: Penguin Books, 1969), pp. 135-74.

56. Bennett, Theatre Audiences, p. 97.

57. In this respect it is interesting to note the ambiguity between the 'embedding' of members of the audience in the deep box space (Italian model), and its frame, frequently reminiscent of the proscenium arch.

58. Ridout, Stage Fright, p. 77.

59. For a discussion of the aesthetic claims and perceptual qualities of the 'black effects. Exposure bears on a fundamentally unstable and ambiguous state-that one is an observer and observed at the same time. This ambiguity becomes still more complex, as exposure operates within these distinct spatial components. For a performer, accustomed to relations among fellow performers within the space of the scene, such dual stature would appear as but one dimension of his condition, a part of the craft. Yet, paradoxically, for a participant in the auditorium such ambiguity might surface quite unexpectedly.

The idea that members of the audience, too, actually tend to rely on preconceptions associating exposure as a circumstance of the performer emerges when 'being observed' is imagined as a cause of distinct discomfort. ${ }^{56}$ Indeed, there is a difference in the ways in which exposure is experienced. For the actor, bound to occupy the vortex of its major spatial mechanisms and forces, exposure underlies and accounts for the intensity of the notorious state of stage fright. Yet for the participator in the auditorium, exposure is actualized at its most dubious, and its disconcerting momentum is 'safe', due to the ensuing view-hencepower-over the event, the side-by-side alignment with fellow participants, and the stability of the seat down to its backrest. These would account for its subdued form, or delayed recognition in encounter. The sense of exposure is more apt to surface in explicit circumstances, or manipulations, that undermine apparent accommodation in space: ${ }^{57}$ when one is set within a steeper slope, perched on the edge, less protected, laid open to the influence of subtle but turbulent forces and impulses, in constant awareness of others. Exposure emerges with special intensity in cases where the stage is inserted into the field of the spectators (horseshoe, theatre-in-the-round), whereby relations amongst them become direct. The sense of exposure is enhanced as participators of the audience are decisively placed as a background to adjacent action on stage, rendering them strikingly liable, prone to observation in the very same way as the performer.

Such topological instantiations of exposure, then, are accompanied by darkness, a customary circumstance of performance. Dimming the lights is a device employed to avert from distracting detail and foster attention, emphasizing the action on stage. As a circumstance made possible by relatively recent developments in theatre technology, and employed within particular conventions (excluding, for instance, 'even white space' modes), darkness is regarded as advantageous in that it allows members of the audience to retreat into the anonymity of a 'safe seat in darkness', 'withdraw from presence', ${ }^{58}$ or retain privacy. ${ }^{59}$ Yet darkness might assume a role in destabilizing, and in diversifying fear-related effects, for example bringing forth those of spatial disorientation. It exerts effects on perception, dissolving the physical definitions of space, irrespective of their surface treatment. It has the capacity to frustrate the senses, and thus deprive the spectator of the possibility of locating the self within an overall legible scheme. Hence for the agent 'placed' in the dark, it undermines the 'certainty' and 'safety' of a seat, turning into a sense of being arrested, held within an indeterminate and elusive matter: dark space. For the agent in the spotlight it takes the form of facing onlookers who are virtually absent and triggers the peculiar sense of darkness looking back. 
box' theatre, see

Wiles, A Short

History, pp. 254-59.

While its 'blackness'

is thought to

diminish arousal (p.

257), from the

standpoint of this

present study it could

be argued that as

'any' space, it would

rather stimulate that

arousal which is

linked to fear in

confusion. In this

respect, the 'black

box theatre', though

not always necessarily

'dark', presents a

special case in

reducing perception

of spatial boundaries

through special

treatment of the

physical enclosure.

60. This claim is supported not least by the notion of 'situational personality' that expresses the interdependence of identity and context, based on the observation that the behaviour of an individual varies more under different conditions than the behaviour of different individuals under the same conditions. See Juhani Plasmaa, 'Identity, Intimacy and Domicile Notes on the Phenomenology of Home', in The Home: Words,

Interpretations, Meanings, and Environments, ed. by David N. Benjamin (Aldershot: Avebury, 1995), pp. 131-50 (p. 137).

61. Langer, Mind, pp. 122 (p. 7).

62. Aaron, Stage Fright, p. 125 .

63. Langer, Mind, p. 9

64. Ibid., p. 12 .

\section{A Form of Experience}

Evidently the site does not actually pose any real threat. Yet it poses challenges, for the controversial charges of exposure and darkness are deeply entrenched in space and, reverberate in the 'situated body'. ${ }^{60}$ Validating the absorbing qualities of the immediate, these are viscerally felt, as much a potential for response to sensibility as a pathway to awareness, especially while, acknowledged by the body, they condense in a fairly stable cluster of discrete occurrences and processes that constitute a form of experience.

The anxiety, which lends this form of experience its distinctive character, generates from within spatial circumstances that linger at the verge between the comfortable and the disconcerting, the reassuring and the unnerving. They invoke liability and risk: such as that of the 'exposed' that is readily associated with lack (of vitality, strength and ability to resist), as well as, paradoxically, that of the 'because of', for being oriented outwards and concerned with its act. There are circumstances, such as darkness, that would even obstruct the perception of physical footholds for consciousness, stirring elemental fears: circumstances that actualize a semi-physical, semiapprehending condition - the interval where anxiety is at its most intense.

All of the ingredients pertinent to this form of experience enhance anxiety, though it may fade into the subconscious. Yet these ingredients are also driven by it. And it is precisely this interval of fear - the 'feeling phase' ${ }^{61}$ of the total phenomenon - which alerts, mobilizes, and supports an immersion in the moment, the immediate circumstances, and the action. For the actor on stage, this immersion helps to transform fear into the 'elated states' ${ }^{62}$ underlying the vigour of artistic performance. Analogously, it is anxiety that supplies the energy for mere participants (conceived as self-contained individuals who, as source, precede acts and preclude experience) to engage and go through change in the course of the event, as much producers as products of the experience in question.

The mental events of this form of experience begin with the 'mode of feeling', which is triggered from without and perceived as 'induced'. ${ }^{63}$ These events are born in an unmediated (bodily) discovery of vulnerability: imparted by an entanglement in uncertainty, by a confrontation with, and oscillation among, experientially inverse conditions (active/passive, observer/observed, subverted/intervening), or, perhaps still more radically, by a deterioration of the sense of corporeality as essential constituent of the self - an affect of dark space. Yet, though they initiate as possibilities for response to physical circumstances and situations, they evolve into possibilities that are acquired: they are apt to shift into the mode which is felt as 'autogenic action' ${ }^{64}$ and hence which is more properly present to the mind. It can be construed that this transition is stimulated though the 'drama' embedded in space, and intensified through fear. Exposure evokes the sense of being apart and distinct from the acute discernment of one's situation and self. It is the same circumstance that instigates a keen awareness of the other, which 
65. The reference here is to the liberating potential of vulnerability, as concisely discussed by Fiona Jenkins in 'Plurality, Dialogue and Response: Addressing

Vulnerability', Contretemps, 3 (2002), 85-97. Explored in the context of dialogue, vulnerability, in contrast to tolerance is rather conceived in terms of receptivity, permeability and generosity, connoting the openness of identity to transformation.

66. This aspect of human mentality is profoundly presented in Yates, The Art of Memory, in the context of consequent theories of the mind and corresponding techniques to enhance/expand memory.

67. This function of 'others' seeing and hearing is asserted in the context of the public space of the city by Hannah Arendt, in 'The Public Realm: The Common', in The Public Face of Architecture: Civic Culture and Public Spaces, ed. by Nathan Glazer and Mark Lila New York and London: Free Press, 1987), pp. 5-12.

68. Hans Georg Gadamer, Truth and Method (New York: Continuum, 1996), pp. 55-70. In his essay 'The Aesthetics of Genius and the Concept of Experience (Erlebnis)', the notion of 'genuine experience' is elaborated through its central furthers the capacity to relate and expand. Yet it is the particular way in which these affect the minute sense of 'crisis' that invites the complex processes of conceiving and accepting the liability of reciprocal reversals, and the intrinsic coexistence of these controversial aspects. Exposure thereby cultivates the ability to acknowledge the self/other, or to recuperate compassion; it, furthermore, allows these abilities to reach the level of faculties: converting vulnerability into the power to be affected, ${ }^{65}$ and witnessing into the assimilation of change.

Witnessing, quite distinct from 'seeing', is an act and practice where one is simultaneously participator, observer and observed. It is constructed through exposure and facilitated best in places that sustain a constant awareness of all the other fellow participants. This state on the one hand requires observance and responsibility, and hence amounts to becoming conscious over one's diverse roles in a common endeavour. On the other hand, it works towards confirming the reality of anything undergone at the site by way of having discerned one's own, as well as everyone else's, presence in space. This allows associating intangibles (affective states, feelings, insights) with the immediate physical framework - that is, imposing a form on that which would otherwise remain only a period of time, ${ }^{66}$ and attaining awareness over occurrences as articulate experiential ingredients. Hence, witnessing stabilizes; it 'objectifies' by lending credibility to a private feeling, ${ }^{67}$ a state, or an act. It thus helps one to grasp and commit to memory that which has been experienced, allowing a safe reconstruction.

Contemplating exposure as a form of experience points to two distinct phases in the course of its evolvement, and illustrates their predominant nature: the preceding (being spontaneous, pre-intellectual, explorative) confirming the constitutive capacities of the corporeal and affective, and its conversion into complex mental events marking the second 'autogenous' phase. This helps infer a structure of this form of experience in terms of the instances/phases of 'destabilization' and 'stabilization', analogous perhaps to those of experience per se, ${ }^{68}$ and renders it explicit through its most tangible component - space. Space actualizes its constitutive capacities, which consist of reproducing the experience by framing and engendering these instances simultaneously, as a perpetual choice, and opportunity.

\section{Concluding Remarks}

Inquiry through exposure, conceived to be generic for the theatre's mode of spatial organization, and employed as an analytical and interpretative tool, has helped to articulate space's performance as a dynamic constituent of experience. It engenders and aids the appropriation of ingredients which are productive for all participants involved, as well as being relevant to the understanding of operations of fear at performance. Examining the conceptual implications of exposure and dark space has enabled an articulation of the spatial logic underlying their workings in terms of mechanisms, situations and relations, along with their links to anxiety and fear. Analysis of their site-specific actualizations has 
mechanism - taking the form of 'negation of former

experience'. It hence necessarily entails a moment where 'the whole of life

consciousness' is affected and engaged in constructing (preservation and dissolution) and assimilating change.

69. It should be noted that within this 'layer' (experiential mode originating in space), 'exposure', though perceived as the most 'affective', would interplay with other 'generic' conditions and/or forms of experience such as 'isolation', or 'collective containment'. For a conceptualization of these as a framework to a more systematic analysis of particular theatre spaces, refer to Öztürk, 'Through the Body'.

70. Insofar as issues of character and authenticity of the theatrical are discussed in reference to the site in its entirety, two particular configurations come forth: the playhouse, in that it constitutes relations at their most intense and enhances mutual influence that characterizes experience (Mackintosh, Architecture); and the horseshoe or arena type as the prime configuration that, in itself, by showing real and fictional in parallel, supports the dual awareness over the essentially theatrical artifice, and where the highest readiness of audience to participate can be observed. See particularized this spatial logic in terms of the specified effects of different configurations, and prepared a basis to perceive the intensity of the theatre experience. Exploration of the form of experience established grounds to infer its potential weight within experience in performance.

In its capacity as conceptual construct, the concept of exposure renders space experientially consequential and thereby accesses a layer of experience at the existential level previously unaccounted for. ${ }^{69}$ It has helped to particularize and recover a range of discrete processes as ingredients in performance, generating grounds to reassess concerns with space. At a theoretical level, the recognition of such a layer of experience might offer a complementary dimension in discussing the intensity, character, and authenticity of the theatrical. ${ }^{70}$ For it articulates legitimate aspects pertaining to the experience of theatre: it issues from the corporeality of the site, engenders a mode of being which entails immersion in the moment, is suffused with feelings, and on its own terms enhances the possibility of turning participators into more properly performing agents. In this respect it is revealing to notice that configurations highlighted as epitomizing theatre (the playhouse and the theatre-in-the-round) at the same time present cases where constructions of exposure and fear actualize at their most acute. The emergence of affective qualities in these cases appears to be traceable to features underlying the spatial intensity of the ancient Greek prototype. It also hints at the presence of certain ritual-based strategies that build on the agency of space in facing fear. The significance of this 'layer' lies in the fact that not only does it involve dispositions (concentration, activation, compassion) appropriate to the acts of performance and perception of theatrical content, but it goes beyond these to entail the 'productivity' of structures of fear embedded in exposure, which, during a particular performance, presents a permanent potential at the verge of awareness. Foregrounded by the play, experience of space tends to remain preconscious. Yet the ingredients of the experience of exposure are apt to emerge to consciousness as plausible candidates to participate in and invigorate experience in performance, affirming performance as engagement (distinct from performance as distraction) through pleasure that derives from effort invested in undergoing and incorporating change.

In correlation with diverse theatre cultures, this form of experience tends to reverberate with classical drama performances as encoded in 'official' productions, with the unsettling engagement achieved in the 'studio' or 'workshop' around contemporary dramatic writing, and with the seriousness of ritual enactment in non-western theatre. It is enhanced through performance practices that violate conventions, where reversing relations and displacing agents bear on the intensity of the experience of both the relations and the effects of exposure. As a persistent quality it tends to come forth more vigorously in smaller theatre spaces, while monumental ones overwhelm, or simply reduce the affects of space. It is more tangible in spaces of stern, sober character, devoid of the distraction of opulent decoration.

With respect to the diverse spatial practices in performance, awareness of the spatial constitution and mechanisms of exposure and its affective impetus might assist those involved in the expressive appropriation of space in gesture and posture. The idea of exposure is relevant to staging strategies, especially 
Stephen Purcell, 'A Shared

Experience: Shakespeare and Popular Theatre', Performance Research, 10.3 (September 2005), 74-84. those that seek to experiment and undermine the comfort of established attitudes and preconceptions, where articulation through unexpected effects might strikingly diversify spatiality, and augment the ambiguity of the theatrical situation. The concept could inform the practice of architecture, which, by designating the permanent features of theatre space at various levels, could recover, amplify, and formalize affective capacities of space. Awareness of these, and the reassertion of corresponding design principles in addition to those ensuring comfort and sightlines, bear on new constructions, the adaptation of existing buildings for theatrical use, and the renovation of inherited historical theatres.

Inquiry through exposure expands on the accounts of fear in the context of performance by specifying the terms in which fear is insinuated through space, suggesting that at the site structures of fear might actually be omnipresent. It allows the corporeal constitution of fear and/or anxiety to emerge, by rendering its generation, operations, and techniques for productive transformation and dissolution at the individual level tangible, inscribed in physical space, and stretched in duration. It also points to the potentialities of the site with regard to agoraphobia, alienation, and angst, which can be attended to exclusively at a collective setting and through collective strategies.

In a broader context, such an examination of the site allows the links to various frameworks reflecting on 'experience-as-an-encounter' with regard to the ontological possibilities embedded therein to acquire tangibility and become visible. Such resonance rests, again, in the corporeality of the site, which, as a consummate manifestation of exposure, engenders the elemental condition of physical encounter. In this, the exploration of and through exposure helps not only extract the spatial logic underlying the experience of the performance event as encounter, it also allows for a particularizing encounter within its physical actualization at the site (in terms of structuring instances, the operation of affects, and the constitution of a range of possible occurrences at micro level). Moreover, inquiry in terms of exposure helps conceive of certain intricate, perhaps even intrinsic, mechanisms of such selfconstitutive acts, for the site reproduces a rudimentary but thoroughly corporeal 'interruption' - ek-stasis-where space assumes the status of a pivot, suggesting, through the body, the possibility of multiple trespassings. These incursions indicate not only that processes at this level do enable the emergence of 'performative' states and ultimately shifts in the conscious mind, but also articulate their intimate entanglement with fear.

This perspective, ascertaining the capacity of space to formalize, intensify and sustain conditions and thus render experiential ingredients discernible, helps us to conceive of the site as a socio-cultural context, apt to engender sensibilities, cultivate capacities and exercise faculties. It shows that experience in/through space frames and supports the actualization of such ontological functions not only within the aesthetic and through the performative event, but also on its own terms, instating the site as the corporeal component of theatrical praxis. It offers the opportunity to construe a performative process, which evolves through different modalities of experience, engages different levels of consciousness, and is embedded in the corporeal. 